\title{
Culture learning in a daily space of kitchen: the case of Korean digital kitchen
}

\author{
Jaeuk Park ${ }^{*}$ (1)
}

${ }^{*}$ Correspondence:

j.u.park@leeds.ac.uk

School of Languages,

Cultures and Societies,

University of Leeds, Leeds LS2

9JT, UK

\begin{abstract}
The rapid advancement of technology has allowed computer-assisted language learning (CALL) to have made inroads in the area of pedagogy for language and culture learning. While the majority of studies have used online and virtual environments for culture learning, very little attention has been paid to a real world environment. This study is based on a digital kitchen where students can learn foreign language, culture and cuisine at the same time through cooking tasks. Learning cultural aspects can be properly realised via cooking because the daily activity provides a window into culture, and the digital kitchen provides users with opportunities to directly encounter the target culture themselves via cooking and tasting. 48 international participants conducted two cooking sessions, one in a digital kitchen using real objects and the other in a classroom by looking at typical pictures/photos in a textbook. A range of data sources were employed, such as questionnaires, semi-structured interviews and video-observations to answer the research question. It was found that students learned foreign cultural aspects better when in direct engagement in a digital kitchen by handling actual items than when in a classroom by simply using photos. This study contributes to the development of the real world learning environment for culture learning via innovative technology.
\end{abstract}

Keywords: CALL, Digital kitchen, Multimodal learning space, Culture, Food and cooking

\section{Introduction}

As new technology evolves, more and more people from different cultures interact with each other. These social changes require people to obtain a series of skills necessary in our lives, including language and culture knowledge: 'if we want to teach language and culture and access layers of culture which are particularly difficult to access, we need the right tools' (Levet \& Waryb, 2006, p. 95). This calls on L2 educators to take into consideration intercultural competence as one of the important objectives in foreign language education.

New methods and technologies have opened up a range of opportunities for learning skills necessary for life, giving access to real-connection in real-world environments. The advancement of new technology and its technological affordances has been embraced by many educators to help L2 learners and to bring enriching educational experiences priate credit to the original author(s) and the source, provide a link to the Creative Commons licence, and indicate if changes were made. The images or other third party material in this article are included in the article's Creative Commons licence, unless indicated otherwise in a credit line to the material. If material is not included in the article's Creative Commons licence and your intended use is not permitted by statutory regulation or exceeds the permitted use, you will need to obtain permission directly from the copyright holder. To view a copy of this licence, visit http://creativecommons.org/licenses/by/4.0/. 
to their classrooms (Ho, 2013). However, the technology has yet to see its full potential in the field of foreign language and culture learning. This study attempts to achieve part of the potential. By adopting a real world learning environment of a digital kitchen (Seedhouse, 2017), this paper aims to report on whether the latest technological developments help promote foreign culture learning and how learning occurs.

\section{Literature review}

\section{Digital kitchen}

The digital kitchen is a real world learning environment of a daily kitchen where students can learn foreign language, culture and cuisine at the same time through cooking tasks (Seedhouse, 2017; Park et al., 2016). This study employs the innovative space for several reasons (Park et al., 2016). Firstly, various well-known problems relating to foreign culture learning in online and virtual environments can be addressed. Students have long been given pedagogical tasks which make them experience the cultural aspects, rather than actually encountering the target culture to perform real world activities. The Korean Digital Kitchen (KDK) allowed learners to be engaged in a real world task of physically making the dish. Secondly, there has been a difficulty of bringing the foreign culture to life in the classroom. Learners in the KDK are required to produce the local cuisine, which offers a window into the culture by manipulating real objects involving the five senses: 'The relationship among language, food and culture in a society is an inextricable one' (Ayeomoni, 2011, p. 51). Thirdly, motivation is activated, therefore enhancing learning in this study. Many people find state-of-the-art technology an interesting and motivating tool for learning as can be seen in a number of learning platforms. Sensor-based Nintendo $\mathrm{Wii}^{\mathrm{TM}}$ involves multimodal technology-based activity, and its popularity and motivation is evident according to users' feedback: 'Wonderful technology'; 'The sensors were cool'; 'I said that it was fun to do and that it's great that you can do something practical whilst learning languages and different recipes and I really like the idea and the technology' (Seedhouse, 2017, p. 6). Furthermore, cookery plays an important part in increasing motivation. More and more countries across the world have seen an increasing number and range of cookbooks and cooking programs on TV. These reflect people's interests and enjoyment in relation to cooking. In other words, motivation from technology and cuisines is stimulated in a digital kitchen environment.

\section{Culture learning}

The understandings of the culture has echoed in the range of approaches and techniques, which have been supported for culture learning (Furstenberg et al., 2001; Kramsch \& Andersen, 1999; Liddicoat \& Crozet, 2000; Lo Bianco \& Crozet, 2003; O’Dowd, 2003). This research has shown how the approaches and techniques can help teachers and learners in cultural learning. Nevertheless, there is no consensus on the definition and content of culture learning as culture is a multifaceted and complicated topic depending on the context. This may explain why it has recently been suggested that it is no longer meaningless to attempt to define culture. It is now more useful to consider specific contexts or practices, because 'culture in all its meanings and with all its affiliated concepts, is situational' (Blommaert, 1998, p. 8). In other words, culture has numerous definitions because of its complex nature and also because of practitioners bringing their 
own perspectives to their descriptions. Instead of using culture as the focal point of definition, the current research uses the term of 'cultural experience'-encountering another way of life (Moran, 2001).

Moran (2001) defines culture as 'the evolving way of life of a group of persons, consisting of a shared set of practices associated with a shared set of products, based upon a shared set of perspectives on the world, and set within specific social contexts' (p. 24). He based his definition of culture on five interrelated dimensions (see Moran, 2001 for a full account); cultural products refers to tangible forms such as artefacts of things and places or physical settings; cultural practices involve all the actions that individuals of the culture carry out as part of their way of life, including language; cultural perspectives are the explicit and implicit meanings shared by members of the culture, such as perceptions, beliefs, values, and attitudes; cultural communities mean the specific groups of the culture where individuals perform practices in a specific setting; cultural persons indicate personal way of living a shared way of life through unique interpretation of the culture. According to his claims, the cultural phenomenon includes real structures (products) that social members of the culture (persons) employ in a range of interactions (practices) in specific social circumstances (communities) in such ways that reflect their values, attitudes, and beliefs (perspectives). In other words, the way of life itself is the cultural content and learning process occurring via the cultural encounter (ibid). Applying Moran's explanation, the current research constructs and employs two learning environments for cultural learning: a classroom and a daily space of the kitchen where students encounter Korean cultural aspects, share their own experiences, and reflect their perceptions by experiencing the cooking of typical Korean dishes.

Understanding foreign culture enhances language learning. It has been emphasised that L2 learning is incomplete without learning culture (Thanasoulas, 2001). Bada (2000) claims that 'the need for cultural literacy in ELT arises mainly from the fact that most language learners, not exposed to cultural elements of the society in question, seem to encounter significant hardship in communicating meaning to native speakers' (p. 101). This indicates that culture learning is necessary as cultural knowledge plays a part in communication.

In cultural learning, it is important for learners to be able to 'reflect on their native culture, synthesize information about other cultures as well as other related disciplines, and actively construct their own understanding of the target culture' (Ho, 2013, p. 311). What comprehensively reflects these thoughts is Moran's (2001) approach for cultural experience, which enhances an in-depth understanding of culture through a progressive educational process. He explains that the cultural experience refers to learners' encounter or involvement of any kind with another way of life through learning materials in learning environments, and 'these encounters elicit four kinds of culture learning, or cultural knowings: knowing about, knowing how, knowing why, and knowing oneself' (p. 8). Moran's framework for cultural knowings includes four components that are involved in the learning interaction as below (Table 1).

Learning interactions according to Moran lead to cultural knowledge, through which learners transform their intellectual state from unaware to aware as they encounter a new way of life. A wide range of factors exert influences on culture learning, such as learners' characteristics, the relationship between the learners' culture and the target 
Table 1 Moran's cultural experience

$\begin{array}{ll}\begin{array}{l}\text { Knowing about } \\ \text { Knowing how }\end{array} & \begin{array}{l}\text { Showing acquisition of general and detailed cultural information about the specific culture } \\ \text { Obtaining cultural practices such as behaviours, touching, looking, or other forms of 'doing' } \\ \text { via the use of technological tools and their language to establish relationship with the target } \\ \text { culture }\end{array} \\ \text { Knowing why } & \begin{array}{l}\text { Enriching an understanding of the fundamental cultural perspectives through observations } \\ \text { and experiences } \\ \text { Knowing oneself }\end{array}\end{array}$

culture, the instructional context, the teacher-student relationship, and cultural comparisons (Moran, 2001). Likewise, this framework underpins the design of learning tasks and shows the process of cultural learning, which is why this scheme is applied to the current project.

Learning cultural aspects can be realised via cooking because the mundane activity provides a window into culture (Seedhouse, 2017). As Kurlansky (2004) puts it, 'food is a central activity of mankind and one of the single most significant trademarks of a culture' (p. 11). Furthermore, Trubek and Belliveau (2009) see the notion of cooking as pedagogy with an activity involving 'multisensory experiential learning' because cooking itself 'engages students at an almost instinctive level; the smells, sounds, sights, textures and tastes excite senses and intellects' (ibid., p. 16). Indeed, cooking and eating food is one of the only things in the world that draws on all five senses to engage people. Thus, cultural knowledge and learning can be obtained through foods and cuisine.

Spurred by the rapid advancement of technology, Computer-Assisted Language Learning (CALL) has made inroads in the area of pedagogy for culture learning. Email exchange projects between native and non-native speakers of English have been conducted to see the effects on intercultural learning, and this was shown to facilitate cultural understanding via cross-cultural email interactions (O'Dowd, 2003). While the asynchronous nature of email enabled learners with valuable opportunities to take enough time to think about themselves which allowed for reflection and representation of cultural understanding, the synchronous connection via chat made spontaneous response possible, enhancing active culture learning (Toyoda \& Harrison, 2002; Tudini, 2003). Hanna and de Nooy (2003) established an authentic Internet forum run by the French newspaper Le Monde in which English speakers were engaged in a particular cultural practice. It was authentic as it was designed and intended not for language learners of French, but for bringing forth a set of cultural norms and expected behaviours. Furthermore, a web-based project Cultura has appeared as a kind of mode of learning about other cultures. It was designed based on interactive process in which students from different cultures are made available to share their ideas on specific cultural aspects reciprocally. Levet and Waryb (2006) have recently advanced the online platform where two groups of students studying in a similar setting from France and America are presented with similar materials and shared their viewpoints on those materials, and they contributed to providing a mode of learning for culture learning. Moreover, online spaces such as Active Worlds and Second life offer opportunities to experience cultures from other countries. Both programs are an avatar-based multi-user virtual environment, allowing for interaction with one another in a range of situations through avatars that represent 
the individual users (Peterson, 2006; Stevens, 2006). They found that the mix of technical affordances allowed users to be able to carry out a variety of tasks through target language interaction, which led to culture learning. Among the most recent application of computer technology to culture learning has been Ho's (2013) research in which social media is used as a learning platform for Vietnamese students. Thus, computer technology has been used and applied as a resource for culture learning in addition to language learning.

Nonetheless, it is limited in that the majority of studies have focused on the learning effect of simple virtual spaces, rather than a real world environment. To address this issue, computer experts and applied linguists have contributed to creating a real world learning environment of the Digital Kitchen, and hence pushed the boundaries of knowledge in the field (Olivier et al., 2009; Preston et al., 2015; Seedhouse, 2017; Seedhouse et al., 2013, 2014). Yet, little has been done on cultural aspects in the projects nor have the researchers identified what factors contribute to culture learning. This is the gap this research tries to bridge using the Oriental language of Korean. The purpose of this study is therefore to investigate specifically whether engaging all senses in a digital kitchen helps to promote foreign culture learning and how it contributes to learning. In order to clearly examine how the technology helps learning, a traditional learning environment of the classroom is used for comparison. In designing the test, the following research question was formulated: Does using real objects to cook in the digital kitchen help students learn foreign cultural aspects more than looking at photos of the objects in the classroom? If so, how? By using a real world environment in combination with digital technology on global culture learning, this study contributes to expanding the applicability of the learning environment in the field of applied linguistics.

\section{Methods}

Participants

Participants consisted of 48 adults of both British and international origins, living in Newcastle, UK. Being from 20 different international backgrounds, the participants' ages ranged from 19 to 49 years old. All participants were absolute beginners in Korean language and cultural understanding.

\section{Data collection and analysis}

Questionnaires were used as they help researchers collect information from respondents (Bryman, 2012). Closed and open-ended questions were implemented as they are useful to gather data on participants' feelings and opinions (Kumar, 1999). Participants were asked their degree of agreement with a series of statements on how they perceive a digital kitchen and a classroom in relation to culture learning and whether or not the key difference in resources available in both settings influence learning. This study utilised two more data sets consisting of interviews and observations. The semi-structured interviews were used for in-depth investigation and this approach helped examine possible issues that were highlighted through the questionnaire (Borg \& Gall, 1989). The observations provided researchers with a very powerful tool for gaining insight into the situation, helping to see things that might otherwise be missed and to discover things 
that participants might not freely talk about in interview situations (Cohen et al., 2011). Thus, this study used three sets of data for triangulation.

A paired-samples t-test was used as it can show whether there is a statistically significant difference in the mean scores for the two groups and the same group on two occasions (Cronk, 2012). To analyse the figures within a data set, several measures were used, such as mean $(M)$, mean difference $(M D)$, standard deviation $(S D)$, t-test $(t)$, and probability $(p): p$ value $<0.005$ indicates a significant difference (Cohen, 1988). The questionnaire included four closed questions. All items in the questionnaire were assigned a numerical value and rated on a 5 point scale according to Fowler (2008): Strongly Agree $(\mathrm{SA}=1)$, Agree $(\mathrm{A}=2)$, Neutral $(\mathrm{N}=3)$, Disagree $(\mathrm{D}=4)$, Strongly Disagree $(\mathrm{SD}=5)$. So, the lower the means are, the more strongly participants agree with each statement in the questionnaires and vice versa. That is, the mean scores close to 1 indicate strong agreement. The number was given to four decimal places in SPSS and Excel spreadsheets and they were all rounded to two significant figures.

Thematic analysis was employed to investigate interviews as it is a flexible research tool providing a rich and detailed account of data (Braun \& Clarke, 2006). The thematic focus in the interview analysis was participants' comments on their own experiences in the two different environments. In order to analyse observational data, Conversation Analysis (CA), a methodology for the analysis of naturally occurring spoken interaction, was used to portray participants' learning process in two cooking sessions. The nature of the observation offers the possibility to gather authentic data from real-world settings, which is a unique strength of this data collection instrument (Cohen et al., 2011). Observational data also help researchers see things that might otherwise be unconsciously missed and to discover things that participants might not freely talk about in interview situations. Whereas interviews offer why it was being done, CA provides what was going on in two learning environments and how learning was acquired (DeCuir-Gunby et al., 2011).

\section{Different learning experience in two settings}

To determine which environment is more conducive to culture learning, users needed to carry out two recipes ("Appendix 1") in the two locations. Each session lasted for 20-25 min. Each pair conducted two cooking sessions: first with a recipe in a classroom, and then with another recipe in a digital kitchen. In order to control practice effects and ordering effects, two recipes were created for two different locations. In summary, the design required four groups, two locations and two different recipes with no overlapping language and cultural aspects. The experimental design of Latin Square was made possible as shown below in Fig. 1. Every condition, including the procedures of tasks and tests was controlled so that a potential confounding variable can be minimised.

The difference between the two settings is that participants in the kitchen used real objects to cook, whereas they simply only used photos of objects in the classroom. This means that the kitchen users could use all of five senses, while classroom learners could have only accessed a few senses. In the two different settings, learners went through the exactly same task procedures in each cooking session. Given the nature of the classroom, learners did simulate cooking by interacting with a teacher using the computer, which was not sensor-based. Teacher involvement was minimised. They were, however, 


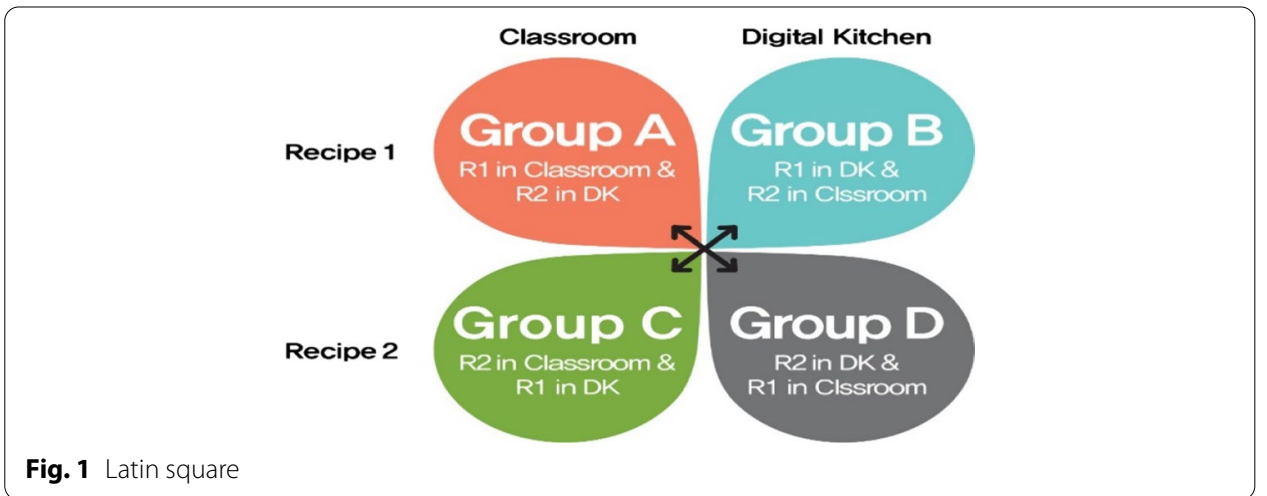

Fig. 1 Latin square
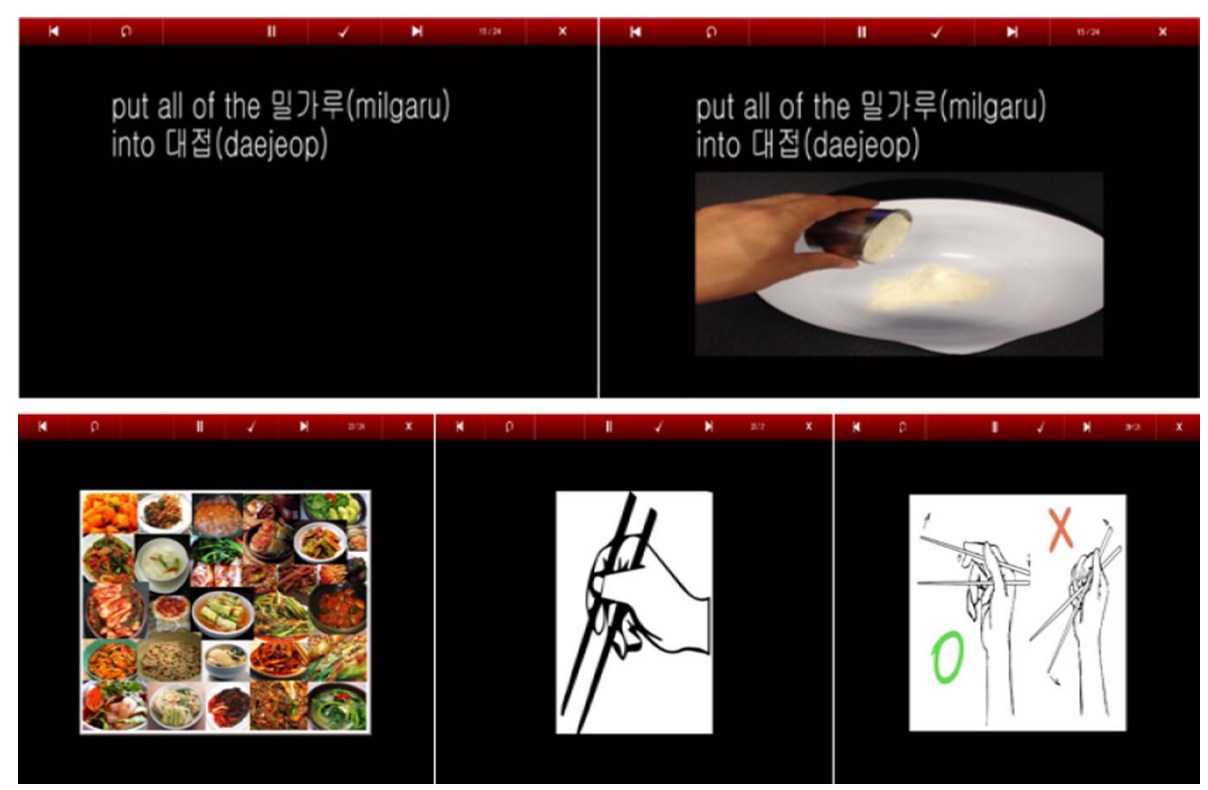

Fig. 2 Explanation on cultural aspects

offered the same feedback as in the kitchen upon their request. A computer tablet called Graphic User Interface (GUI) provided users with every single step of instructions to complete the dish in Fig. 2.

The computer (GUI) tablet was specifically designed to reinforce learning processes. It therefore guides learners through the cooking process and allows the users to manually request situated support. Throughout the three task phases, the GUI offered four types of scaffolding: an audio and audio-visual help for the object with Korean and Roman letterings written to use, feedback, a repetition request, and the option of moving backwards and forwards through the list of ingredients for users to double check. English language was used when explaining cultural aspects of how chopsticks are used in Korea.

Learners encountered Korean cultural aspects (Fig. 2) throughout three tasks via explicit explanations on a certain aspect in two environments alike. However, the learners' experiences were different; digital kitchen users were able to use all five senses, but classroom learners could only use a few senses as shown in Fig. 3. 


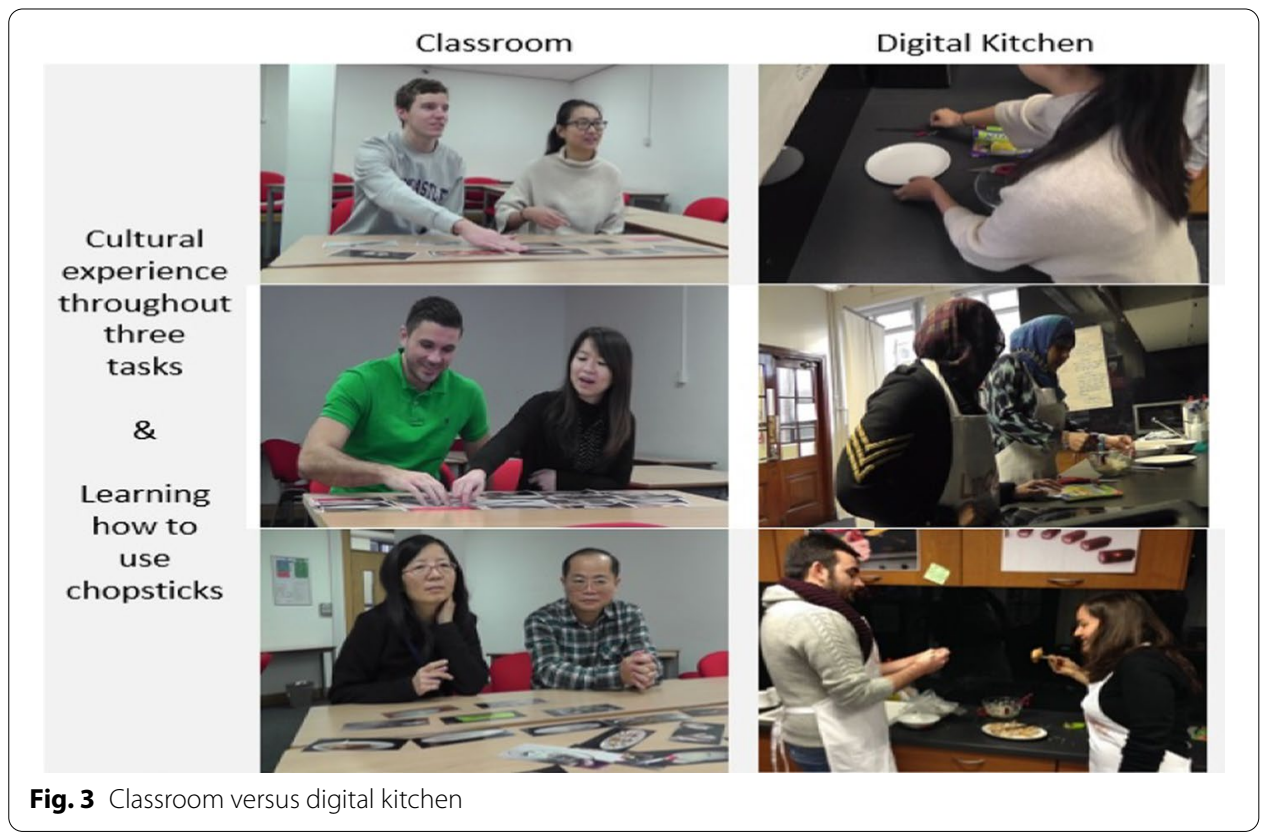

Table 2 Preferences toward two learning settings

\begin{tabular}{|c|c|c|c|c|c|c|}
\hline & & Mean & $\mathrm{N}$ & SD & $\mathrm{t}$ & $p$ \\
\hline Q1 & $\begin{array}{l}\text { I liked to learn a foreign language } \\
\text { and culture in the classroom } \\
\text { (Class) }\end{array}$ & 2.27 & 48 & 0.92 & & \\
\hline Q2 & $\begin{array}{l}\text { I liked to learn a foreign language } \\
\text { and culture in a kitchen environ- } \\
\text { ment (DK) }\end{array}$ & 1.29 & 48 & 0.58 & & \\
\hline Q1-Q2 & Class_-digital kitchen (DK) & 0.98 & & 1.06 & 6.40 & 0.00 \\
\hline
\end{tabular}

\section{Results}

\subsection{Preferences and learning modes toward two settings}

A paired samples t-test was conducted to evaluate the impact of the intervention on students' scores on students' preference toward the two different environments of a classroom and a digital kitchen as in Table 2.

There was a statistically significant decrease in 'preference' scores from Q1 $(M=2.27, S D=0.92)$ to $\mathrm{Q} 2(M=1.29, S D=0.58)$. The statistics of learners' responses show that the mean difference $(M D=0.98)$ is statistically significant $t(47)=6.40$, $p<0.00$ (two-tailed). Therefore, the digital kitchen was preferred to a classroom in terms of learning a foreign language and culture. What was conducted to further explore if learning modes makes a difference in their learning preference was the next Table 3.

This also shows a statistically significant decrease in scores from Q3 $(M=1.56$, $S D=0.68)$ to $\mathrm{Q} 4(M=1.29, S D=0.50)$. The mean difference $(M D=0.27)$ in two environments reached statistical significance $t(47)=2.22, p<0.03$ (two-tailed). This reveals how learners perceive their experiences in two settings-being able to use real objects to cook the dish helps them to learn more effectively than just using photos in a classroom. 
Table 3 Paired-sampled T-test on learning modes

\begin{tabular}{lllllll}
\hline & Mean & N & SD & t & p \\
\hline Q3 & $\begin{array}{l}\text { Using photos of real objects in } \\
\text { the classroom contributed to my } \\
\text { learning (Photos) }\end{array}$ & 1.56 & 48 & 0.68 & & \\
Q4 & $\begin{array}{l}\text { Using real objects in digital } \\
\text { kitchen contributed to my learn- } \\
\text { ing (real objects) } \\
\text { Photos-real objects }\end{array}$ & 1.29 & 48 & 0.50 & & \\
Q3-Q4 & 0.27 & & 0.84 & 2.22 & 0.03 \\
\hline
\end{tabular}

Table 4 Languages and scripts used in the transcripts

\begin{tabular}{cll}
\hline Korean in Korean script & Korean in Roman script & \multicolumn{1}{c}{ English translation } \\
\hline 자 이제 맛있게 먹어봅시다 & $\begin{array}{l}\text { ja ije matitge } \\
\text { meogeobopsida }\end{array}$ & $\begin{array}{l}\text { wow well done now enjoy the } \\
\text { food as you like }\end{array}$ \\
\hline
\end{tabular}

That is, they found learning in a digital kitchen more enjoyable and interesting than in a classroom. This might contribute to significantly higher level of learning in a kitchen.

Thus, students found the digital kitchen and physical objects more useful and helpful to learn cultural aspects. This indicates that students are familiar with visual aids in learning (Paivio \& Desrochers, 1981), but want one more dimension to enhance learning: touch (Nattinger, 1988).

Having said that learners had a higher motivational level for the digital kitchen environment than in the traditional classroom, the next section shifts the focus to understanding the processes of learning by analysing what happens in the two environments which might account for this difference.

\section{Learning process}

In order to be able to compare interaction of 'cultural knowings' in the two settings, based on Moran's (2001), sequences from each setting were chosen from the same step on during-task in the same recipe where users were trying to understand how to use chopsticks. The Korean language used in the episodes is transcribed in both Korean and Roman scripts and translated into English as in Table 4, in addition to CA conventions ("Appendix 2"). CA transcripts are combined with interview verbatims to answer the research question and support the argument.

How individuals use kitchen utensils depends on cultural background, as different cultures have their own ways of handling them. In Korean culture, people often use chopsticks when eating food. The two settings asked learners to use the utensil to eat the dish on a plate. This is where users' cultural experience and learning occurs.

Episodes below show that the Korean Digital Kitchen (KDK) plays an integral role in the culture learning process. Before tasting, the KDK provided a detailed explanation about how to use chopsticks as part of the task, allowing learners to acquire cultural information (knowing about). The fact that users experience cultural practices 'by cooking' the authentic Korean dish helps them establish a relationship with the Korean culture (knowing how). 


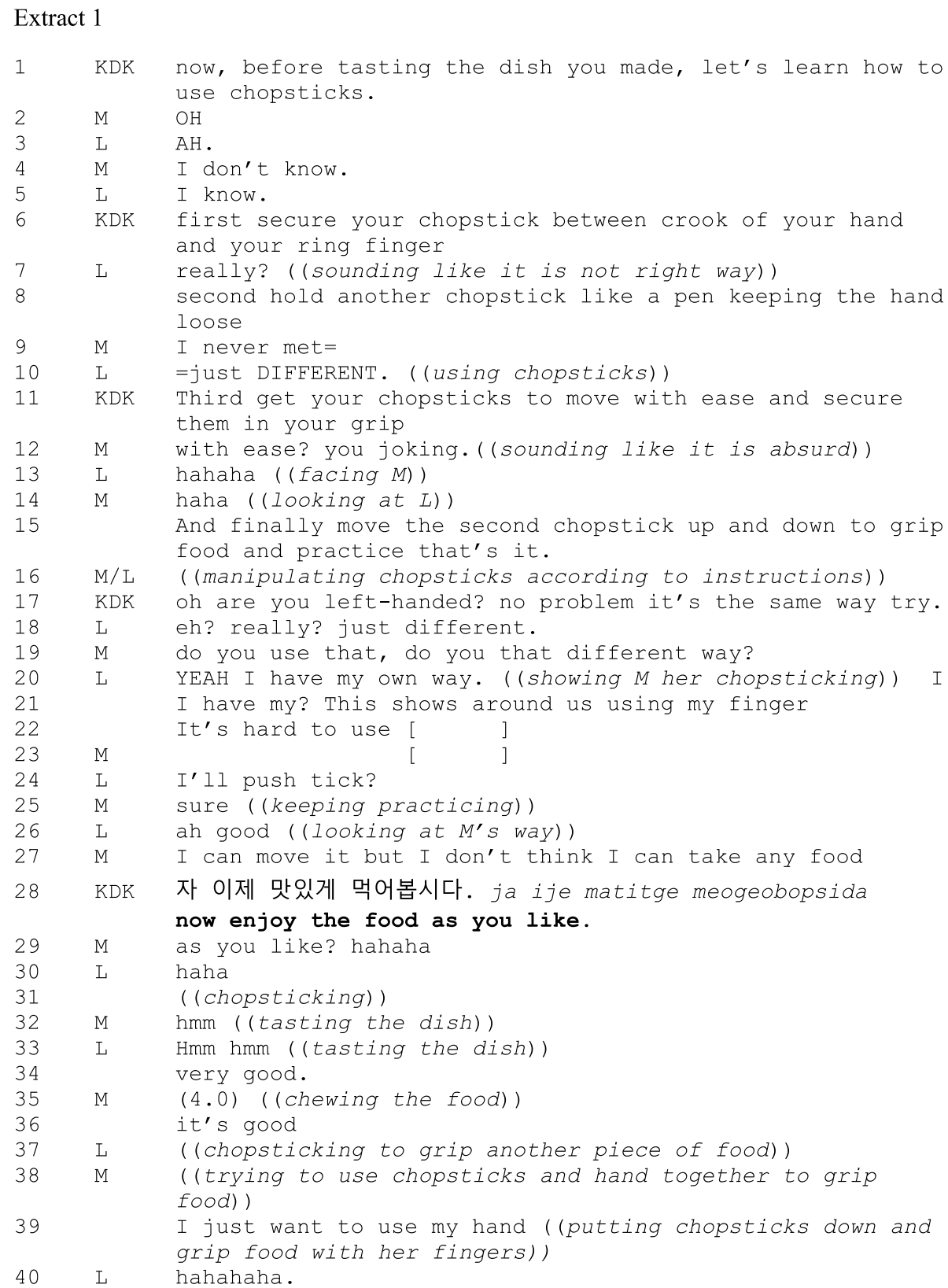

Lines 1 and 9 within Extract 12 below demonstrate the current state of learners' cultural knowledge. $\mathrm{M}$ from Romania explicitly acknowledges her lack of skills in using chopsticks (line 4), whereas L from China finds the explanation different from the Chinese way of manipulating chopsticks (line 10). The explanation continues to help users, but their reactions are the same. No matter what kind of guidance the KDK provides, the two learners from different cultural backgrounds do not follow the instructions. M makes fun of the KDK by repeating the explanation to indicate she cannot do as told (line 12) and L is still displaying her doubtfulness (line 18). Although a concern about difference and difficulty in cultural practices arises, they adjust to the new experience 
of foreign culture. In particular, $M$ does so by orientating to physical touching and practice, and L by manipulating chopsticks in her own way to get the hang of it. This shows how the duo enrich their cultural understanding (knowing why). So, M slowly makes gradual progress, which causes L to compliment her development (line 26). Both of them eventually pick up a piece of the dish and eat it with chopsticks, enjoying the taste of the food. Their positive evaluations of the food displays obvious enjoyment (line 34-36). These evaluations demonstrate a raised self-awareness of the target culture (knowing oneself). Nevertheless, at the end, $\mathrm{M}$ wants to stick to her own way. It is because she as a Romanian is accustomed to using a fork. Eventually, in lines 37-40, she puts the chopsticks down on the desk and uses her fingers instead.

This cultural learning process is seen not just in making this dish, but also within in the other recipe, kimchijeon in Extract 2 below. The users went through the different recipe and consequently, a different cultural aspect. Two learners below were given an explanation about kimchi, a main material for their task, before tasting it (knowing about). There were no chopsticks in this recipe, but surprisingly, one participant asks for real chopsticks to use (knowing how). Two users show two different forms of learning in culture, S about kimchi and MA about chopsticks. S's comments on Koreans' health status clearly displays her understanding in line 2 (as in Fig. 3) for GUI's previous explanation, whereas $M$ focuses mainly on properly using the chopsticks in lines $3-7$ by repeatedly practising it. These moments exhibit clear signs of their cultural knowledge transforming from receptive to productive (knowing why). MA eventually picks up a slice of the food and eats it, showing his reaction in line 7. S and MA's verbal embodiments clearly display their enjoyment. These evaluations demonstrate they gradually understand the target culture (knowing oneself) (Fig. 4).

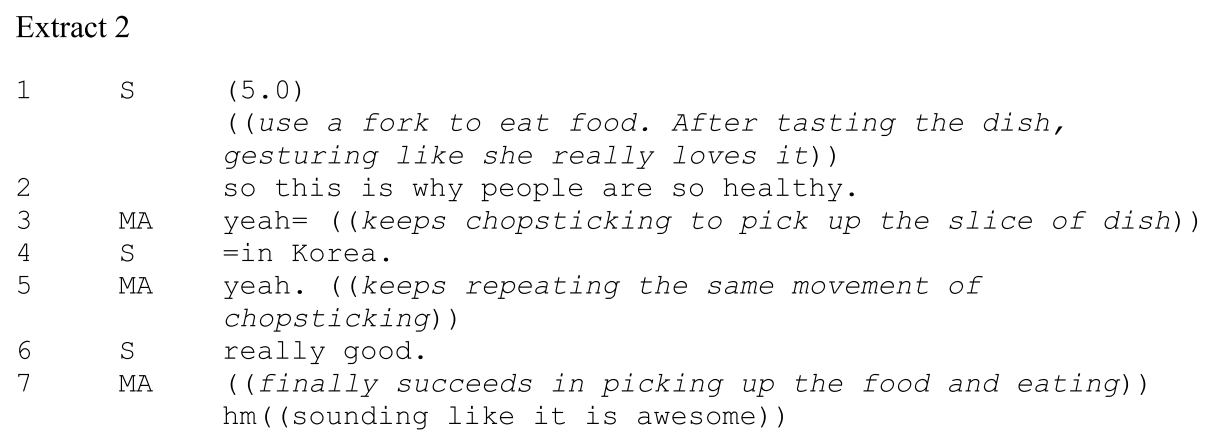

These two examples show how the kitchen environment is oriented to learners, who co-construct the organisation of the talk. The duo demonstrates the mutual orientation to taking advantage of the food and equipment in a digital kitchen, all of which serve as mediators that help learners not just to be exposed to specific cultural context, but to carry it out themselves by either tasting or practicing. Hence, this leads to an understanding of Korean cultural aspects of people and food; all senses are employed and pleased. They could physically use the objects to cook the dish and to savour it. This is demonstrative of the fact that the everyday environment provides a learning space which supplies learners with actual objects and offers them better opportunities to enhance learning outcomes. 


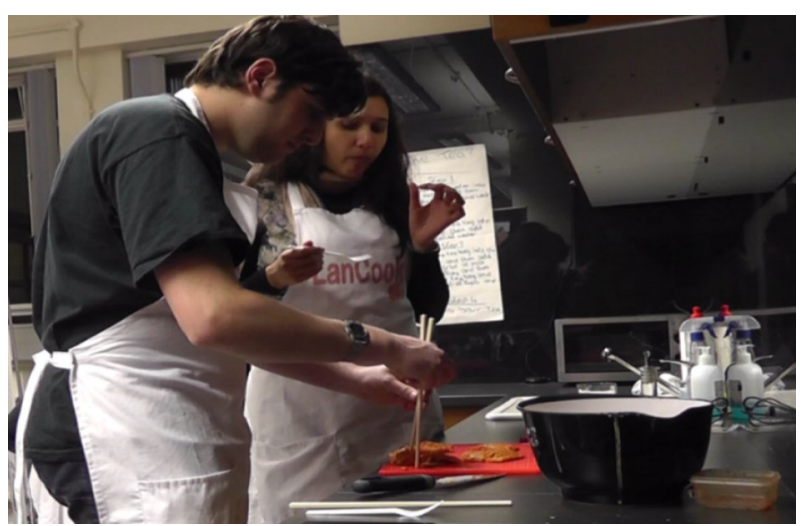

Fig. 4 "So, this is why people are so healthy in Korea"

The power of using real objects is shown in their self-report as well. The duo and other learners made it clear how the kitchen helps learn foreign cultural aspects and how learning is enhanced as below:

Ok well the taste, and the smell actually, of course you know what exactly is. In the picture, you can imagine but maybe without experiencing, experiencing anything like this, we imagine something it rather than experience. So I think actual holding and touching objects, it helps me more.

We had a purpose to cook whereas in the classroom, it was something interesting to know about but what should I do with that information afterward? But whereas now, I can I can cook the dish and I can talk about some cultural aspects of South Korea, which enhances not only my language learning but my cultural background. When they say, well it's spicy, you have to do this with cabbage. And you are thinking oh yeah it tasted like you know like chilly and very spicy, so you could relate what you are actually eating to the cultural aspect. It's not something abstract that somebody else tells you like oh it's spicy so you're actually experiencing it.

They commented on using real objects and how it brought back memories from their own culture to compare. This is important because learning occurs. Fantini (1999) sees cultural comparisons as a transformative learning process, and evidently the KDK provided learners with a space in which their own cultures are recalled. Actual resources (using chopsticks and eating foods) are seen as a powerful mediator to raise awareness of cultural similarity and difference, thus fostering cultural learning. However, the classroom learning showed a different mood.

The Extract 3 below came from a classroom where students were given an explanation of cultural aspects of how to use chopsticks and they attempted to try it out. Unlike the digital kitchen which offers real objects to cook the dish, the classroom 
learners were given photos instead of actual objects meaning users had limited access to manipulating the chopsticks as they want in this episode. Learners look unsatisfied with having no access to what they want.

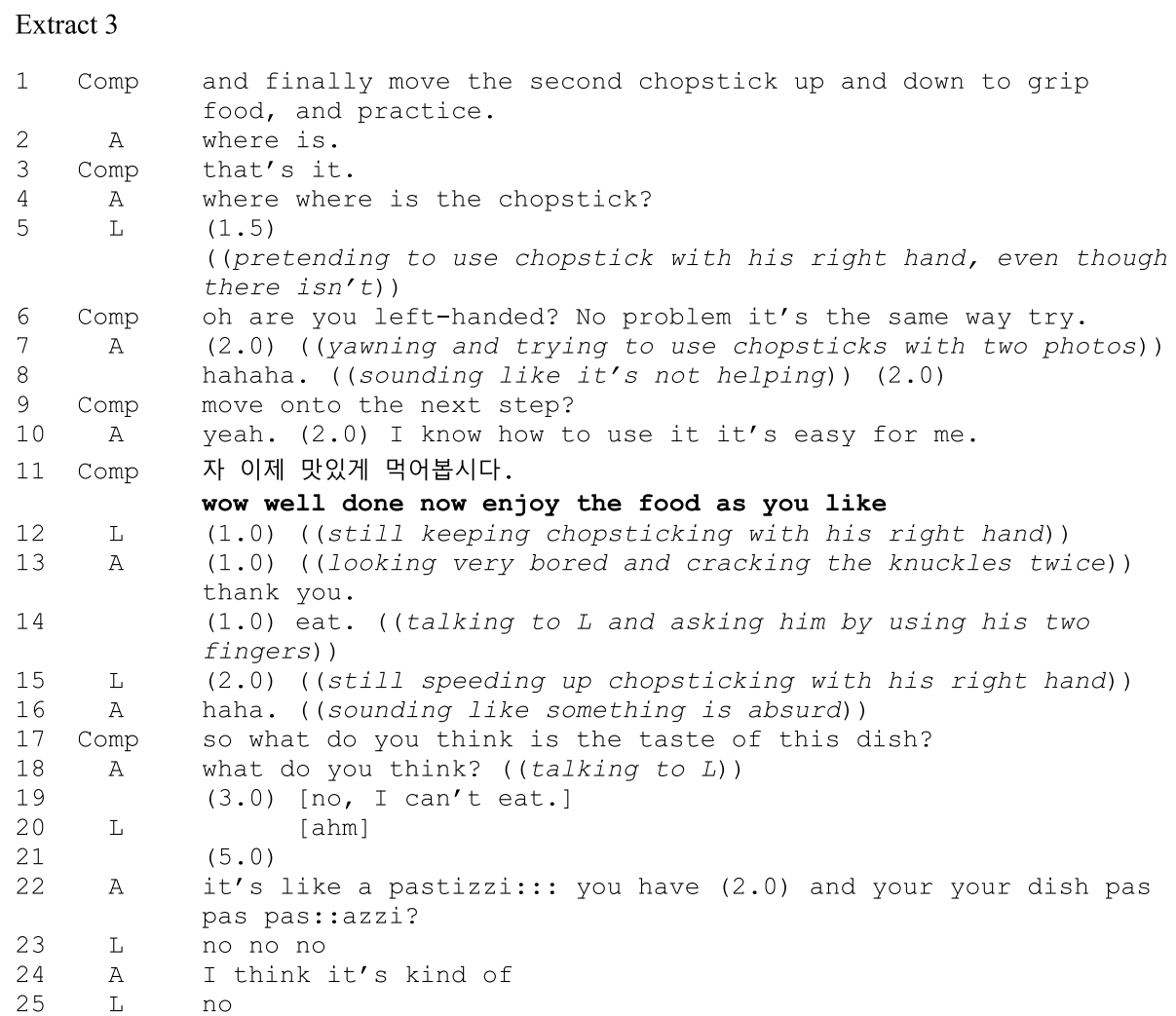

Even before a teacher's explanation is completed (knowing about), A asks for access to actual chopsticks in lines 1-6. He shows explicit boredom with their task and just follows the teacher's instructions by pretending to use chopsticks with two photos in lines 7 and 8 (knowing how). A's disinterest seems to be repeatedly displayed when he shows clear gestures of cracking his knuckles twice, and asks $\mathrm{L}$ to get engaged in the instruction through a reluctant smile in lines $13-14$ as in Fig. 5. In the meantime, L reluctantly mimics the instructions as shown on a Power Point screen in lines 5, 12, and 15 (knowing why). There is no sign of enjoyment nor excitement in their interaction. When asked about the taste, A straightforwardly explains that there is no way he can evaluate the dish in line 19 . He just goes on to describe the taste only by the look of the dish and their own experience in line 22.

Furthermore, when asked about the taste in the next sequence of Extract 4, A describes exactly what he saw, but rising intonations in his explanation in line 2 apparently demonstrates that he is not confident not convinced (Knowing oneself). 


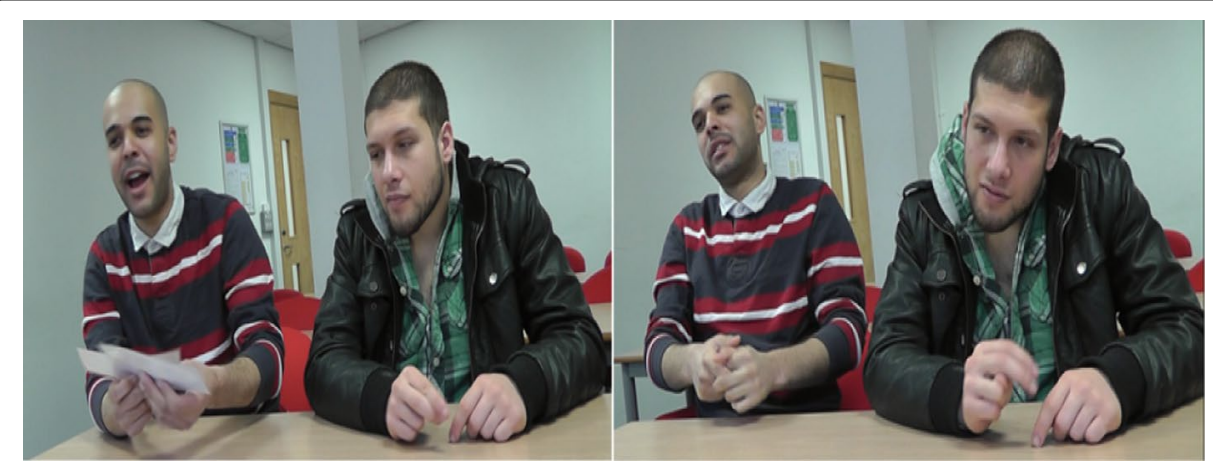

Fig. 5 Boredom in lines 7, 8 and 13

\section{Extract 4}

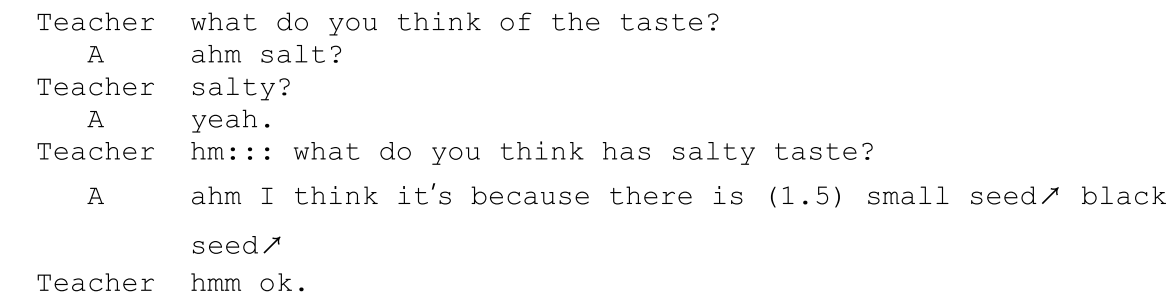

Thus, the absence of real objects led to the ongoing lack of cultural understandings, which subsequently kept the duo away from cultural awareness. Simply using photos gave them no choice but to use their imagination to answer the question related to taste, causing less of knowing how. It therefore depleted their enthusiasm, worsening knowing why, which brought about less of knowing oneself. It was obvious that lack of physicality made a big difference, hindering their learning process of cultural aspects. Interviews with $\mathrm{L}$ and other learners demonstrate short but clear attitude as below:

With the picture, I don't know how to put it and how to feel, and how to put it.

I think it wouldn't be possible. We can imagine but we are not sure whether we are able to handle chopsticks if it's in the classroom.

I don't know how to use chopsticks and I must say that all in the classroom experience which we had. I haven't even learned how to use chopsticks. And so it wasn't very helpful in terms of cultural learning. And I think you can ask photograph on the internet.

Because when we talk about culture, sometimes, it's very vague and abstract if you don't experience any of it, but if you experience it, then you totally, you will be totally successful introduce the culture to others and to promote other people's interest to know more.

\section{Digital kitchen versus classroom}

Test results showed significant differences in culture learning between the classroom and the KDK, demonstrating the preference of a digital kitchen over a classroom. These 
learning and attitude products from quantitative data were triangulated when learning processes were revealed and integrated with qualitative evidence.

A series of interactional episodes allowed for similarities and differences, which help to compare the two environments. In the two settings alike, learners were able to interact with one another in performing their tasks to complete the dish-making. They all ended up learning cultural knowledge of a foreign country. However, there were factors that made a difference in learning. The digital kitchen created a learning space in which learners were able to have more opportunities to negotiate the meaning and convey the knowledge to each other, whereas a classroom provided learners with less chances to interact with each other. Distinctively, physical objects enabled students to feel like they were making a real dish, establishing a space in which they could associate the object with their memory in terms of cultural knowledge. In the classroom, on the other hand, the only thing they could employ was their imagination. In other words, the digital kitchen allows for all five dimensions (textual, auditory, visual, tactile and kinaesthetic) to be utilised, whereas the classroom allowed three dimensions (textual, auditory and visual). All these points led to different levels of motivation and engagement, which subsequently contributed to contrasting levels of learning processes in two different learning environments. This is not to claim learning did not occur in a classroom; learners certainly did learn cultural aspects, according to interview transcriptions in general.

\section{Discussion}

As learners encountered a different way of life, they could experience four interconnected learning interactions in both settings alike: four cultural knowings. The everyday environment of a kitchen generated a more desirable learning space in which learners used actual objects to experience the target culture. This provided learners with better opportunities to enhance cultural 'knowings', whereas the traditional setting makes consecutive disconnections to learners' cultural involvement, hindering their learning process of cultural aspects. Physicality seems to be integral.

The findings resonate with previous research that examined how multimodal methods of computer-mediated communication tasks led language learners to use various channels in interactions (Satar, 2016) and produce better speaking proficiency (Satar \& ÖZdener, 2008). Wigham (2017) demonstrates how multimodal communication strategies in webconferencing-supported pedagogy enhance foreign language teaching. The three studies show a significant difference in favour of multimodality. The KDK went extra miles by establishing a real world space. This study provided specific information about physical food ingredients and equipment, the workplace, the rules and regulations, and the responsibilities of people who work there (knowing about). The cooking itself is a form of 'doing' (Ellis, 2003), entailing learners' direct participation and engagement in the everyday life of Korean people according to Koreans' food customs and traditions. Cooking involves using physically authentic tools (knowing how). Learners carried out a cooking task in the manner of Korean people through a range of cultural practices such as touching, looking, saying, and using body movements and other non-verbal communication cues. Thus, first-hand engagement offers learners an opportunity to directly encounter another way of life themselves. 
The importance of direct experience in a foreign culture is also confirmed by a Japanese EFL teacher's description (Moran, 2001, p. 132); 'this experience gave me an awareness that knowing from direct, concrete experience was quite different from knowing through intellectual information. I believe that experience helps people gain more real, powerful, and deeper understanding of themselves'. It showed that the real practices help learners establish a genuine relationship with the target culture. It can be interpreted that in the digital kitchen, learners were able to be given a chance to encounter an authentic way of foreign life and to understand the way through carrying out a real world task of cooking. This means learners may change their behaviour to develop Korean-ness appropriately in order to adapt and integrate into Korean culture. In contrast, a classroom did not provide learners with the powerful mediator to bridge the gap for actual cultural encounters. As a result, it was limited to learn and adapt to the target culture. In this sense, it can be said that using all five senses plays an instrumental role in enriching culture experience and learning.

These findings suggest implications for those planning to design and implement a similar real world learning environment as seen in the Digital Kitchen. The actual environment was characterised by affordances in which the kinaesthetic mode can be ensured, allowing students to directly encounter another way of life. The kitchen turned out to be a more enriching environment for learning in which the atmosphere of interaction and the level of motivation via cooking is unrivalled to virtual learning platforms. Therefore, the real world learning environment might be taken more into consideration as a resource for cultural learning as well as foreign language learning.

\section{Conclusion}

Following Seedhouse's (2017) notion of multimodal learning experience, the study sought to examine to what extent physical manipulation with real objects affects foreign culture learning in comparison with when only photos are used in the classroom. This was considered important in light of the issues related to a task-based learning method inside the classroom context (Seedhouse et al., 2013, 2014). It turned out that the technology-embedded environment itself helped co-construct the active interaction, which allowed for meaningful communication between learners. More importantly, physical objects enabled them to use their five senses, which offered a different level of motivation, thereby promoting cultural learning outcomes.

There are, however, limitations, which present possible directions for further research. Although this research has shown the difference between touching the real objects and seeing photos on culture learning, there were other confounding variables that might be responsible for the outcomes. They include using the objects to perform a meaningful real world task, involving all senses, and being able to self-organise learning using environmental support. It is not clear which factor primarily leads to significant difference. Therefore, further research at this point in conjunction with using new languages and cuisines, would be recommended. Furthermore, this study has not demonstrated empirical data for culture learning. As it is complicated to measure culture learning, future research might involve more controlled experiments where users' actual knowledge of cultural aspects can be assessed. 


\section{Appendix 1}

\section{김치전 (kimchijeon, kimchi pancake)}

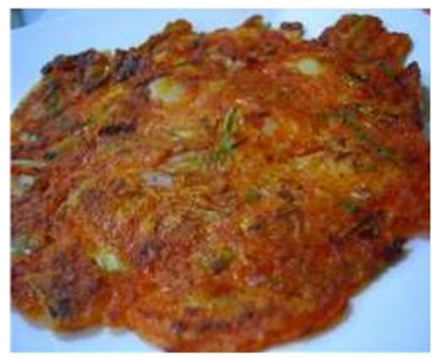

\section{※ Recipe}

Ingredients: a cup of kimchi, $250 \mathrm{~g}$ of flour, a cup of water, oil

Equipment: a frying pan, a chopping board, a knife, a bowl, a spatula, a whisk

\section{Directions}

1. In a bowl, place chopped kimchi, flour (all purpose flour), and $1 / 4$ cup of water and mix it well with a spoon.

2. Heat up a 12 inch non-stick pan over medium high heat and drizzle about 2 tbs grape seed oil.

3. Place the mixture of kimchi pancake batter on the pan and spread it thinly and evenly with a spoon.

4. Cook it for 2 to 3 minutes until the bottom gets golden brown and crispy.

5. Turn it over with a spatula or flip it.

6. Lower the heat to medium and cook for another 2 minutes.

7. Turn it over one more time and cook for 30 seconds before transferring it to a serving plate. *tip: Serve it right out of the pan or cool it down and cut it into bite size to serve.

※ Application of the recipe fit for the current study

Target Vocabulary items: Kimchi (김치), flour (밀가루), water (물), oil (식용유), a frying pan (후라이팬), a chopping board (도마), a knife (칼), a big bowl (대법), a spatula (뒤집개), a whisk (거품기)

\begin{tabular}{|l|l|l|}
\hline \multicolumn{1}{|c|}{ Pre-task } & \multicolumn{1}{|c|}{ During-task } & Post-task \\
\hline 1. Bring kimchi & 1. Put oil into a frying pan & 1. Now, enjoy the \\
2. Bring flour & 2. Heat the frying pan with mid-low fire & dish as you like \\
3. Bring water & 3. Put flour into a big bowl & \\
4. Bring oil & 4. Put water into a big bowl & \\
5. Bring a frying pan & 5. Put kimchi into a big bowl & \\
6. Bring a chopping board & 6. Mix them with a whisk & \\
7. Bring a knife & 7. Using a spatula, put the mixture into a & \\
8. Bring a big bowl & frying pan, and make it spread out & \\
9. Bring a spatula & 8. Using a spatula, turn it over in 2 \\
10. Bring a ladle & minutes and turn off in 2 minutes & \\
11. Bring a whisk & 9. Put Kimchi pancake onto a chopping & \\
& board & \\
& 10. Using a knife, cut it as you like & \\
\hline
\end{tabular}




\section{유부초밥 (yubuchobap, rice covered with fried tofu)}

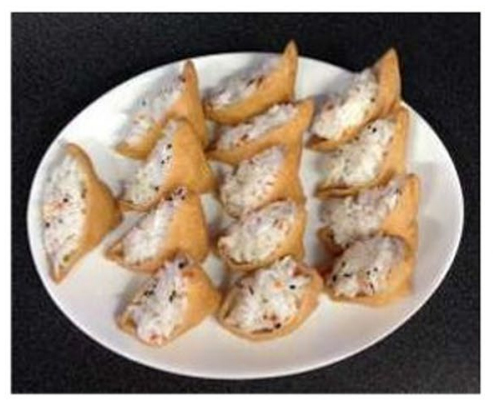

\section{※ Recipe}

Ingredients: fried tofu, a bowl of rice, tofu sauce, dried seasoning

Equipment: chopsticks, a spoon, a bowl, a plate, a vinyl

glove, a scissors

\section{Directions}

1. Put chopped cucumber and carrot into a bowl.

2. Make two cups of rice and put it into a large bowl.

3. Add the vinegar-based sauce to the warm rice, and mix it well with a wooden spoon.

4. Add the prepared vegetables to the rice, and mix it well and cool it down.

5. Open the package of yubu and squeeze it slightly to drain out the extra sauce.

6. Open up each yubu to make a pouch.

7. Fill each tofu pocket with a rice ball.

※ Application of the recipe fit for the current study

Target Vocabulary items: a plate (접시), rice (밥), fried tofu (두부), dried seasoning (조미 양념), sauce (소스), a spoon (숟가락), chopsticks (젓가락), a bowl (대접), a vinyl glove (비닐장갑), a scissors (가위).

\begin{tabular}{|l|l|l|}
\hline \multicolumn{1}{|c|}{ Pre-task } & \multicolumn{1}{|c|}{ During-task } & \multicolumn{1}{c|}{ Post-task } \\
\hline 1. Bring yubu & 1. put bap into geureut & 1. Now, enjoy the \\
2. Bring jomibokkeum & 2. cut chobap soseu with gawi and then & dish as like \\
3. Bring chobap sauce & put it into geureut & \\
4. Bring rice & $\begin{array}{l}\text { 3. cut jomibokkeum with gawi and then } \\
\text { put it into geureut }\end{array}$ & \\
5. Bring a spoon & 4. mix them properly with sutgarak & \\
6. Bring chopsticks & 5. put wisaeng janggap on both hands & \\
7. Bring a bowl & 6. using sutgarak put the mixture into & \\
8. Bring a vinyl glove & yubu and then onto the plate \\
9. Bring a plate & 7. put the rest of yubuchobap on jeopsi & \\
10. Bring a scissor & 8. Now, let's learn how to use chopsticks & \\
& & \\
\end{tabular}

\section{Appendix 2}

CA conventions.

\begin{tabular}{ll}
\hline KDK \& alphabet initial & Each interactant's name \\
\hline[ & Overlapping speech \\
$(($ text $))$ & Annotation of non-verbal activity \\
text & Sounds of Korean letterings learners make \\
text & Text in bold to indicates a translation into English but not talk \\
TEXT & in English produced by speakers \\
\hline
\end{tabular}




\begin{tabular}{ll}
\hline KDK \& alphabet initial & Each interactant's name \\
\hline (Numbers) & the time of a pause in speech \\
$\nearrow \searrow$ & Rising and falling tones \\
$:$ & Prolongation of a sound \\
underline & Indicating the speaker is emphasizing or stressing the speech \\
\hline
\end{tabular}

\section{Abbreviations}

CALL: Computer-assisted language learning; ELT: English language teaching; EFL: English as foreign language; KDK: Korean digital kitchen.

\section{Acknowledgements}

The author would like to thank all who took part in this project. The author acknowledges that the Korean Digital Kitchen (KDK) is one of the by-products of the European Digital Kitchen or LanCook project, funded by an EU grant. The technology is the intellectual property of Newcastle University and was developed there by computing scientists and applied linguists, whose names are acknowledged in Seedhouse (2017, p. xiii). What the Korean Digital Kitchen study contributed was to use the authoring tool software to create new materials for international students to learn Korean language and culture. All data of the KDK belongs to the author of this paper.

\section{Authors' contributions}

This is a single author work. The author(s) read and approved the final manuscript.

\section{Funding}

The author receives no additional external funding.

Availability of data and materials

The datasets used during the current study are available from the author on reasonable request.

\section{Declarations}

\section{Competing interests}

The author declares he has no competing interests.

Received: 17 July 2021 Accepted: 21 November 2021

Published online: 30 November 2021

\section{References}

Ayeomoni, M. O. (2011). Language, food and culture: Implications for language development and expansion in Nigeria. International Journal of Educational Research and Technology, 2(2), 50-55.

Bada, E. (2000). Culture in ELT. Cukurova University Journal of Social Sciences, 6, 100-110.

Blommaert, J. (1998). Different approaches to intercultural communication: A critical survey. Plenary lecture, Lernen und Arbeiten in einer international vernetzten und multikulturellen Gesellschaft, Expertentagung Universität Bremen, Institut für Projektmanagement und Witschaftsinformatik (IPMI), 27-28 February 1998 http://www.cie.ugent.be/CIE/blomm aert1.htm.

Braun, V., \& Clarke, V. (2006). Using thematic analysis in psychology. Qualitative Research in Psychology, 3(2), 77-101. https://doi.org/10.1191/1478088706qp063oa

Bryman, A. (2012). Social research methods (4th ed.). Oxford University Press.

Cohen, J. (1988). Statistical power analysis for the behavioral sciences. Routledge Academic.

Cohen, L., Manion, L., \& Morison, K. (2011). Research methods in education (7th ed.). Routledge.

Cronk, B. (2012). How to use SPSS: A step-by-step guide to analysis and interpretation (7th ed.). Pyrczak Publishing.

DeCuir-Gunby, J. T., Marshall, P. L., \& McCulloch, A. W. (2011). Using mixed methods to analyze video data: A mathematics teacher professional development example. Journal of Mixed Methods Research, 6(3), 199-216.

Ellis, R. (2003). Task-based language learning and teaching. Clarendon Press.

Fowler, F. J. (2008). Survey research methods (4th ed.). Sage.

Furstenberg, G., Levet, S., English, K., \& Maillet, K. (2001). Giving a virtual voice to the silent language of culture: The cultura project. Language Learning and Technology, 5(1), 55-102.

Hanna, B. E., \& de Nooy, J. (2003). A funny thing happened on the way to the forum: Electronic discussion and foreign language learning. Language Learning and Technology, 7(1), 71-85.

Ho, G. A. L. (2013). Use of social media to foster an active construction of understanding through cultural reflection in a foreign language. Electronic Journal of Foreign Language Teaching, 10(1), 309-320.

Kramsch, C., \& Andersen, R. W. (1999). Teaching text and context through multimedia. Language Learning \& Technology, 2(2), 31-42.

Levet, S., \& Waryb, S. (2006). Using the Web to develop students' in-depth understanding of foreign cultural attitudes and values. In R. Donaldson \& M. Haggstrom (Eds.), Changing language education through CALL (pp. 95-118). Routledge. 
Liddicoat, A. J., \& Crozet, C. (2000). Teaching languages, teaching cultures. Applied Linguistics Association of Australia and Language Australia.

Lo Bianco, J., \& Crozet, C. (2003). Teaching invisible culture: Classroom practice and theory. Language Australia Ltd.

Moran, P. R. (2001). Teaching culture: Perspectives in practice. Heinle \& Heinle.

O'Dowd, R. (2003). Understanding the "other side": Intercultural learning in a Spanish-English e-mail exchange. Language Learning \& Technology, 7(2), 118-144.

Olivier, P., Guangyou, X., Monk, A., \& Hoey, J. (2009). Ambient kitchen: designing situated services using a high fidelity prototyping environment. In Proceedings of the 2nd international conference on PErvasive technologies related to assistive environments, Corfu, Greece.

Paivio, A., \& Desrochers, A. (1981). Mnemonic techniques in second language learning. Journal of Educational Psychology, 73, 780-795.

Peterson, M. (2006). Learner interaction management in an avatar and chat-based virtual world. Computer Assisted Language Learning, 19(1), 79-103. https://doi.org/10.1080/09588220600804087

Preston, A., Balaam, M., Seedhouse, P., Kurhila, S., Kotilainen, L., Rafiev, A., Jackson, D., \& Olivier, P. (2015). Can a kitchen teach languages? Linking theory and practice in the design of context-aware language learning environments. Smart Learning Environments, 2(1), 9.

Satar, H. M. (2016). Meaning-making in online language learner interactions via desktop videoconferencing. ReCALL, 28(3), 305-325. https://doi.org/10.1017/S0958344016000100

Satar, H. M., \& ÖZdener, N. (2008). The effects of synchronous CMC on speaking proficiency and anxiety: Text versus voice chat. The Modern Language Journal, 92(4), 595-613. https://doi.org/10.1111/j.1540-4781.2008.00789.x

Seedhouse, P. (2017). Task-based language learning in an immersive digital environment: The European digital kitchen. Bloomsbury.

Seedhouse, P., Preston, A., Olivier, P., Jackson, D., Heslop, P., Balaam, M., Rafiev, A., \& Kipling, M. (2014). The European digital kitchen project. Bellaterra Journal of Teaching \& Learning Language \& Literature, 7(1), 1-16.

Seedhouse, P., Preston, A., Olivier, P., Jackson, D., Heslop, P., Plötz, T., Balaam, M., \& Ali, S. (2013). The French digital kitchen: Implementing task-based language teaching beyond the classroom. International Journal of Computer-Assisted Language Learning and Teaching (IJCALLT), 3(1), 50-72. https://doi.org/10.4018/ijcallt.2013010104

Stevens, V. (2006). Second life in education and language learning. TESL-EJ, 10(3), 1-4.

Thanasoulas, D. (2001). The importance of teaching culture in the foreign language classroom. Radical Pedagogy, 3(3), $1-25$.

Toyoda, E., \& Harrison, R. (2002). Categorization of text chat communication between learners and native speakers of Japanese. Language Learning \& Technology, 6(1), 82-99.

Trubek, A. B., \& Belliveau, C. (2009). Cooking as pedagogy: Engaging the senses through experiential learning. Anthropology News, 50(4), 16-16. https://doi.org/10.1111/j.1556-3502.2009.50416.x

Tudini, V. (2003). Using native speakers in chat. Lanquage Learning \& Technology, 7(3), 141-159.

Wigham, C. (2017). A multimodal analysis of lexical explanation sequences in webconferencing-supported language teaching. Language Learning in Higher Education, 7(1), 81-108.

\section{Publisher's Note}

Springer Nature remains neutral with regard to jurisdictional claims in published maps and institutional affiliations.

\section{Submit your manuscript to a SpringerOpen ${ }^{\circ}$ journal and benefit from:}

- Convenient online submission

- Rigorous peer review

- Open access: articles freely available online

- High visibility within the field

- Retaining the copyright to your article

Submit your next manuscript at $\gg$ springeropen.com 